Revista Triângulo

ISSN 2175-1609

\title{
OS DESAFIOS DOS LÍDERES QUE CONDUZEM A GERAÇÃO Y NA GESTÃO DO CONHECIMENTO
}

\author{
THE CHALLENGES OF LEADERS THAT ARE IN CHARGE OF CONDUCTING THE \\ GENERATION Y IN KNOWLEDGE MANAGEMENT
}

\section{LOS RETOS DE LOS LÍDERES QUE CONDUCEN LA GENERACIÓN Y EN LA GESTIÓN DEL CONOCIMIENTO}

\author{
Karina Yoshie Nakazone \\ E-mail: karinaynakazone@gmail.com \\ Antônio Fernando Gomes Alves \\ E-mail: profalves@uol.com.br \\ Universidade São Judas Tadeu
}

\begin{abstract}
RESUMO
O período Pós-Moderno contribuiu com a utilização de novas tecnologias, permitindo uma otimização nos processos de trabalho e, ao mesmo tempo, um aumento do consumo e da competitividade no mercado. Com isso, o conhecimento tornou-se um ativo intangível de extrema importância para as organizações. A inserção da Geração Y no ambiente de trabalho proporciona maior desafio aos líderes para motivá-los a contribuir com a disseminação do conhecimento. A partir dessa problemática, foi aplicado um questionário para 35 jovens da Geração Y, buscando identificar o nível de satisfação no trabalho, as práticas de GC (Gestão do Conhecimento) aplicadas nas organizações em que trabalham e quais características esperam de um líder. Os resultados mostram jovens insatisfeitos e indiferentes com o trabalho, mas que esperam empatia do líder. Dessa forma, este artigo apresentará os desafios dos líderes que conduzem a Geração Y na Gestão do Conhecimento.
\end{abstract}

PALAVRAS-CHAVE: Geração Y. Gestão do Conhecimento. Liderança.

\section{ABSTRACT}

The Postmodern period contributed to the use of new technologies allowing an optimization in work processes and, at the same time, an increase in market's consumption and competitiveness. Thus, knowledge has become an intangible asset of the utmost importance to organizations. The insertion of the Generation $Y$ into the workplace provides a greater challenge for leaders to motivate them to contribute to the dissemination of knowledge. Based on this problem, a questionnaire was applied to 35 young people from Generation $Y$, seeking to identify the level of work satisfaction, KM (Knowledge Management) practices applied in the organizations where they work, and what characteristics they expect from a leader. The results show young people dissatisfied and indifferent to the job, but who expect empathy from the leader. Therefore, this article will present the challenges of leaders that are in charge of conducting the Generation Y in Knowledge Management.

KEYWORDS: Generation Y. Knowledge Management. Leadership.

\section{RESUMEN}

El período Posmoderno contribuyó con la utilización de nuevas tecnologías, permitiendo una optimización en los procesos de trabajo y, al mismo tiempo, un aumento del consumo y de la competitividad en el mercado. Así, el conocimiento se ha convertido en un activo intangible de extrema importancia para las organizaciones. La inserción de la Generación Y en el ambiente laboral proporciona mayor reto a los líderes para motivarlos a 

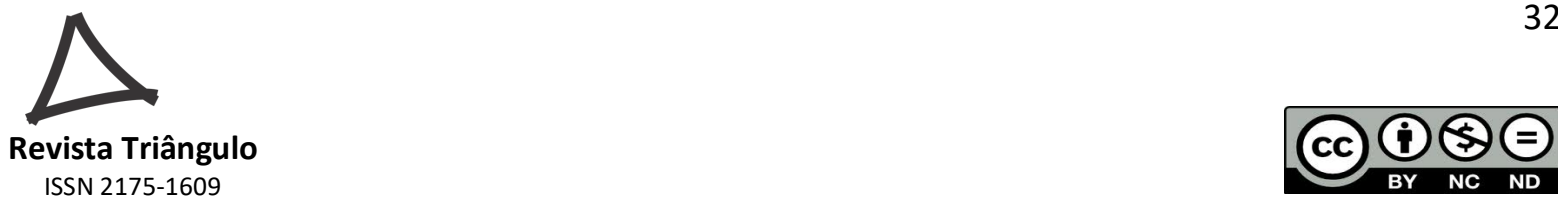

contribuir con la diseminación del conocimiento. A partir de esta problemática, se aplicó un cuestionario para 35 jóvenes de la Generación Y, buscando identificar el nivel de satisfacción en el trabajo, las prácticas de GC (Gestión del Conocimiento) aplicadas en las organizaciones en que trabajan y cuáles características esperan de un lider. Los resultados muestran a jóvenes insatisfechos e indiferentes con el trabajo, pero que esperan empatía del líder. De esa manera, este artículo presentará los retos de los líderes que conducen la Generación Y en la Gestión del Conocimiento.

PALABRAS-CLAVE: Generación Y. Gestión del Conocimiento. Liderazgo.

\section{INTRODUÇÃO}

O período atual, denominado Pós-Moderno, é caracterizado pelo advento da globalização que contribui com o rompimento de barreiras geográficas, permitindo a comunicação entre indivíduos em qualquer lugar do mundo e em tempo real, com a utilização de novas tecnologias.

Este período teve início na transição do fordismo ${ }^{1}$ para a acumulação flexível ${ }^{2}$, cuja introdução de novas tecnologias proporcionou uma redução no tempo de produção, exigindo uma adaptação do trabalhador às mudanças nos processos de trabalho. Ao mesmo tempo, o surgimento do dinheiro de plástico e dos bancos eletrônicos permitiu o aumento do consumo (HARVEY, 2008), acelerando, ainda mais, a dinâmica capitalista.

A Era do Conhecimento iniciou-se nos anos 1970, concomitante ao surgimento do período Pós-Moderno. Longo et al. (2014, p. 18) descreve a importância da Gestão do Conhecimento nas organizações:

O conhecimento é o fator de produção mais importante na economia e reside, essencialmente, nas mentes dos trabalhadores. A gestão estratégica do conhecimento é uma filosofia gerencial que procura organizar esse conhecimento de modo a transformá-lo em vantagem estratégica para as organizações. A gestão do conhecimento surge para gerenciar o capital intelectual, ou seja, o conhecimento que está na mente das pessoas e em suas experiências, com o objetivo de criar diferenciais competitivos para as empresas.

De acordo com Bittencourt (2000), Apud Moreno (2002), as novas fontes de riqueza da Era do Conhecimento são a informação, o conhecimento e a comunicação em vez dos recursos naturais ou do trabalho físico. Tais mudanças são oriundas da globalização.

A Geração Y nasceu diante dessas tecnologias e da Era do Conhecimento. Corresponde aos indivíduos nascidos entre 1982 a 2000 (LANCASTER e STILLMAN, 2011)

${ }^{1} \mathrm{O}$ fordismo é caracterizado pela produção em larga escala, oriunda do capitalismo.

${ }^{2}$ Entende-se por acumulação flexível a "flexibilidade do trabalho, dos mercados de trabalho, dos produtos e padrões de consumo" (HARVEY, 2008, p. 140).

\begin{tabular}{|l|l|l}
\hline $\mathrm{v} .11$ & $\mathrm{n} .2$
\end{tabular}


e são caracterizados como multitarefeiros, buscando no trabalho um significado para suas vidas. Ao contrário da de seus pais, trata-se de uma geração que "espera que as organizações mudem para satisfazer suas necessidades, ao invés de mudarem para satisfazer as necessidades da organização" (LIPKIN e PERRYMORE, 2010, p. 135).

Embora sejam detentores de muita informação, não se cria conhecimento sem a interação entre os indivíduos. A competitividade e o sucesso da organização dependem da sinergia do grupo como um todo e não apenas de um sujeito como detentor do conhecimento, ou seja, é fundamental que seja compartilhado em um processo que ultrapasse os níveis da organização (NONAKA e TAKEUCHI, 1997).

A presença do líder permite o engajamento de seus liderados, trazendo benefícios não somente à organização, mas também ao desenvolvimento de cada indivíduo. De acordo com Cavalcanti et al. (2009), o papel do líder na organização sofreu mudanças, assim como seu comportamento. $\mathrm{O}$ atingimento de metas organizacionais deu espaço para o desenvolvimento de pessoas e de novos líderes.

Dados de uma pesquisa ${ }^{3}$ recente apontam que, para $41 \%$ dos jovens entrevistados, a falta de abertura para fazer diferente dificulta o aprendizado, contra $29 \%$ que se queixam da falta da cultura de troca de conhecimento. Além disso, 71\% dos entrevistados preferem um líder que esteja focado em desenvolver as habilidades da equipe, contra $29 \%$ daqueles que preferem um líder que seja referência em sua área de atuação. Com base nos resultados apresentados nesta pesquisa e diante do contexto exposto, a problemática que define o objeto de estudo se resume na seguinte questão: quais são os desafios e as dificuldades dos líderes da Geração Y no processo de disseminação do conhecimento?

O objetivo geral do presente artigo é refletir sobre os principais desafios do líder da Geração Y na Gestão do Conhecimento, tendo em vista que a conceituação de GC corresponde a um conjunto de processos responsáveis pela criação, pela disseminação e pela utilização do conhecimento para atingir os objetivos da organização, conforme aponta Teixeira Filho e Silva (2002), Apud Longo et. al (2014).

Este estudo apresenta os seguintes objetivos específicos: identificar as principais características das mudanças organizacionais e o impacto no ambiente de trabalho; listar quais

\footnotetext{
${ }^{3}$ Pesquisa realizada pela Cia de Talentos, Carreira dos Sonhos (2017).
} 
comportamentos são desejáveis pelos líderes do século XXI para o sucesso organizacional; observar a percepção que a Geração Y tem em relação ao líder, as expectativas e o relacionamento; divulgar à comunidade científica como o líder poderá contribuir na disseminação do conhecimento na organização diante dos conflitos geracionais e dos obstáculos que impedem seu sucesso.

\section{REFERENCIAL TEÓRICO}

\subsection{Transição da Modernidade à Pós-Modernidade}

Embora o termo Pós-Modernidade seja muito utilizado na atualidade, seu surgimento ocorreu na década de 1930. Segundo Anderson (1999, p. 9-10), o termo Pós-Modernismo começou a ser utilizado por Federico de Onís, que o descreveu como "um refluxo conservador dentro do próprio modernismo: a busca de refúgio contra o seu formidável desafio lírico num perfeccionismo do detalhe e do humor irônico".

Ainda de acordo com Anderson (1999), a ideia inicial de Federico de Onís estava relacionada a movimentos estéticos. A utilização do termo Pós-Modernidade mudou de contexto vinte anos mais tarde para designar uma época.

Analisando a literatura, o termo Pós-Modernidade é encontrado em obras de autores como Lyotard (1988), Harvey (2008), Eagleton (1996), Bauman (1998, 1999, 2001, 2007a, 2007b) e Lipovetsky (2004). Bauman (1998, 1999, 2001, 2007a, 2007b) atribuiu ao termo Pós-Modernidade a Modernidade Líquida, e Lipovetsky (2004) utilizou o termo Hipermodernidade como algo além da Pós-Modernidade, como se lê:

Os indivíduos hipermodernos são ao mesmo tempo mais informados e mais desestruturados, mais adultos e mais instáveis, menos ideológicos e mais tributários das modas, mais abertos e mais influenciáveis, mais críticos e mais superficiais, mais céticos e menos profundos (LIPOVETSKY, 2004, p. 27-28).

O sociólogo polonês Zygmunt Bauman utilizava as metáforas de fluidez ou liquidez para caracterizar a sociedade pós-moderna, ou líquida, conforme se observa em suas obras. Nesse sentido, a ideia de liquidez remetia a uma sociedade mais dinamizada.

Dessa forma, a Pós-Modernidade pode ser definida como 
uma linha de pensamento que questiona as noções clássicas de verdade, razão, identidade e objetividade, a ideia de progresso ou emancipação universal, os sistemas únicos, as grandes narrativas ou os fundamentos definitivos de explicação. [...] vê o mundo como contingente, gratuito, diverso, instável, imprevisível, um conjunto de culturas ou interpretações desunificadas gerando um certo grau de ceticismo em relação à objetividade da verdade, da história e das normas, em relação às idiossincrasias e a coerência de identidades. Essa maneira de ver, como sustentam alguns, baseia-se em circunstâncias concretas: ela emerge da mudança histórica ocorrida no Ocidente para uma nova forma de capitalismo - para o mundo efêmero e descentralizado da tecnologia, do consumismo e da indústria cultural, no qual as indústrias de serviços, finanças e informação triunfam sobre a produção tradicional, e a política clássica de classes cede terreno a uma série difusa de "políticas de identidade" (EAGLETON, 1996, p. 7).

Conforme Eagleton (1996), a Pós-Modernidade difere-se do termo Pós-Modernismo, pois o primeiro caracteriza um período específico, enquanto o segundo corresponde a uma forma de cultura. O mundo efêmero também está associado à Modernidade Líquida de Bauman (2001, 2007a, 2007b, 2008a, 2008b), em que nada é duradouro, mas, sim, fluído, assim como a frase de Marx, "tudo que é sólido desmancha no ar" (BONIFÁCIO, 2014).

Santos (2006), por sua vez, julga inadequada a utilização do termo Pós-Modernidade, pois

O paradigma cultural da modernidade constituiu-se antes de o modo de produção capitalista se ter tornado dominante e extinguir-se-á antes de este último deixar de ser dominante. A sua extinção é complexa porque é em parte um processo de superação e em parte um processo de obsolescência. É superação na medida em que a modernidade cumpriu algumas das suas promessas e, de resto, cumpriu-as em excesso. É obsolescência na medida em que a modernidade está irremediavelmente incapacitada de cumprir outras das suas promessas. Tanto o excesso no cumprimento de algumas das promessas como o déficit no cumprimento de outras são responsáveis pela situação presente, que se apresenta superficialmente como de vazio ou de crise, mas que é, a nível mais profundo, uma situação de transição. Como todas as transições são simultaneamente semicegas e semi-invisíveis, não é possível nomear adequadamente a presente situação. Por esta razão lhe tem sido dado o nome inadequado de pós-modernidade. Mas à falta de melhor, é um nome autêntico na sua inadequação.

(SANTOS, 2006, p. 76-77).

Para Bonifácio (2014), a Modernidade Líquida é marcada pelo consumo, a preocupação com o agora e as incertezas diante do excesso de possibilidades. No trabalho, o sentimento de incerteza também está presente, por conta do enfraquecimento dos laços. Esse 
enfraquecimento associa-se à violação do contrato psicológico ${ }^{4}$. Essa ruptura reduz a lealdade e o compromisso mútuo entre empregado e empregador.

Nesse sentido, é importante compreender a contextualização da chamada PósModernidade para aprofundarmos no comportamento das gerações, como veremos a seguir.

\subsection{As gerações e suas relações com o trabalho}

A palavra geração origina-se do latim generatio, que significa linhagem, ascendência, genealogia (SIGNIFICADOS, 2018). Neste estudo, o termo geração é entendido como grupo de indivíduos com características comuns, como a faixa etária, os valores e as visões de vida (LOMBARDÍA, STEIN e PIN, 2008).

Com o passar dos anos, novas gerações surgem, cada uma com suas características, como veremos adiante.

\subsubsection{Tradicionalistas}

A Geração Tradicionalista compreende os indivíduos nascidos até meados da década de 1940 e, segundo Oliveira (2010), eles presenciaram as guerras mundiais e o período da queda da Bolsa de Nova Iorque em 1929, também conhecido como a Grande Depressão. O maior desafio dessa geração era trabalhar duro para reconstruir o que foi perdido, diante de um cenário repleto de incertezas.

Sob forte influência da cultura militar, os jovens da época fizeram parte de modelos hierárquicos rígidos no trabalho, visando à ordem e à disciplina (OLIVEIRA, 2016). Embora tivessem desejos individualistas, aprenderam a se dedicar totalmente ao trabalho e toda essa dedicação havia um propósito: garantir um futuro melhor para seus filhos.

\subsubsection{Baby boomers}

Os chamados Baby boomers são os "filhos do pós-guerra", conforme Lancaster e Stillman (2011). Tiveram uma vida melhor que a geração anterior, pois a economia estava em ascensão, caracterizando uma visão de mundo otimista.

\footnotetext{
${ }^{4}$ De acordo com Zanelli e Silva (2012), corresponde às expectativas que o empregado possui do empregador e vice-versa.
} 
Embora fossem educados de forma rígida, os Baby boomers questionavam a geração dos seus pais, opondo-se ao conservadorismo e protestando contra o status quo (BONIFÁCIO, 2014 e OLIVEIRA, 2016).

No trabalho, eram considerados competitivos, pois acreditavam que era possível subir na hierarquia cumprindo suas obrigações. Fazer a diferença era apenas para quem alcançasse o topo e a busca pelo poder tornou-se marcante nessa geração.

\subsubsection{Geração X}

Ao contrário dos Baby Boomers, a Geração X corresponde aos indivíduos mais céticos por vivenciarem uma crise econômica no início da década de 1990. O aumento do nível de desemprego e o estouro da bolha da internet aumentaram a preocupação de que o trabalho poderia desaparecer a qualquer momento.

As mães dos indivíduos nascidos durante esse período passaram a trabalhar, e, com isso, os filhos passavam pouco tempo com elas, tornando-se mais independentes. Segundo Oliveira (2016), essa geração tinha o anseio que, trabalhando e conquistando seu dinheiro, haveria maior independência. O trabalho, portanto, passou a ter maior importância, adotandose, assim, o termo workaholic ${ }^{6}$. Embora tivessem maior foco no trabalho, a Geração X buscava o equilíbrio entre vida pessoal e profissional (LANCASTER e STILLMAN, 2011).

\subsubsection{Geração Y}

A Geração Y, também conhecida como Millenials, Geração da Internet, iGeração, Geração do milênio, GenNext, Geração Google e Geração Tech (LIPKIN e PERRYMORE, 2010; BONIFÁCIO, 2014) abrange os indivíduos nascidos entre 1980 e 2000.

Lombardía, Stein e Pin (2008), Lipkin e Perrymore (2010), Lancaster e Stillman (2011) e Bonifácio (2014) elucidam que a Geração Y viveu sob forte proteção dos pais, tornando maior sua dependência, inclusive, na tomada de decisões. Tal comportamento leva a um amadurecimento tardio, afetando suas relações no trabalho.

Essa geração foi criada com a valorização da autoestima, recebendo incentivos e elogios dos pais (LIPKIN e PERRYMORE, 2010; BONIFÁCIO, 2014). No trabalho, esperam

\footnotetext{
${ }^{5}$ Status quo: Expressão do latim que corresponde a uma situação que se encontrava anteriormente (DICIONÁRIO MICHAELIS, 2018). Neste contexto, significa que os baby boomers questionavam a postura conservadora da geração tradicionalista.

${ }^{6}$ Workaholic: termo utilizado para designar indivíduos viciados em trabalho.
} 
o mesmo tratamento e sentem-se frustrados quando não recebem feedback. Lipkin e Perrrymore (2010, p. 135) afirmam que "os jovens Y esperam que as organizações mudem para satisfazer suas necessidades, em vez de eles mudarem para satisfazer as necessidades da organização". Essa ideia vai ao encontro à de Bendassoli e Serafim (2007) que elucidam que os departamentos de Recursos Humanos buscam agradar seus colaboradores com o objetivo de reter talentos por conta da infantilização do adulto, da dependência de ouvir uma opinião e obter algum incentivo na organização.

Diferente da geração anterior, a Geração Y não teme perder o vínculo de trabalho, dando maior importância ao reconhecimento e à identificação com os valores da empresa. Além disso, a busca do equilíbrio entre vida pessoal e profissional tornou-se um fator importante para esses indivíduos.

Outra característica dessa geração é a multitarefa. O uso frequente da tecnologia e, consequentemente, o aumento da velocidade das informações permitiram que os $\mathrm{Y}$ fossem capazes de realizar várias tarefas ao mesmo tempo, segundo Lancaster e Stillman (2011) esclarecem.

Embora o foco deste artigo seja a Geração Y, é importante compreender as gerações antecessoras para que seja possível justificar o comportamento dos $\mathrm{Y}$, pois, de acordo com Bonifácio (2014, p. 36), "cada geração sofre influências específicas da sua geração anterior, que, por sua vez, também foi influenciada por outra geração".

\subsection{Gestão do Conhecimento como vantagem competitiva}

O conhecimento é um dos ativos mais importantes de uma organização. A sua gestão é fundamental para seu crescimento e para a competitividade no mercado. Cada indivíduo detém um conhecimento, em que parte dele vem de suas experiências e outra parte é desenvolvida com o passar do tempo, por meio de informações recebidas e das relações humanas.

Partindo da Filosofia, Nonaka e Takeuchi (1997) relacionam o Conhecimento como uma crença verdadeira justificada introduzida por Platão. Quanto à constituição da fonte de conhecimento, os autores citam duas abordagens à epistemologia na filosofia ocidental: o racionalismo e o empirismo. O racionalismo é produto de um processo mental ideal, em que o conhecimento é obtido por dedução. O empirismo, por sua vez, é resultado da experiência sensorial, na qual o conhecimento é obtido pela indução. 


\subsubsection{Gestão do Conhecimento}

Segundo Zimmer e Leis (2011), o termo Gestão do Conhecimento surgiu na década de 1990. Este termo está atrelado à manutenção da competitividade nas organizações, desde que aplicado adequadamente. Sveiby (1998, p. 3) reforça a ideia de que "a Gestão do Conhecimento não é mais uma moda de eficiência operacional. Faz parte da estratégia empresarial".

Embora seja muito discutida na atualidade, a Gestão do Conhecimento é um tema visto como emergente e possui "um conceito muito fluído e difícil de ser estabelecido fora do contexto organizacional" (Zimmer e Leis, 2011, p. 162).

As relações entre mestre e aprendiz, nos tempos remotos, permitiram um processo de recriação, chamado de tradição por Polanyi, Apud Sveiby (1998). Neste processo, os aprendizes tentavam reproduzir o que seus mestres faziam e, com o passar do tempo, tornavam-se especialistas. Sob o mesmo contexto, Longo et al. (2014) associou à necessidade de as empresas criarem uma cultura de aprendizagem contínua por meio da troca de experiências entre os indivíduos.

\subsubsection{Criação do Conhecimento}

Segundo Nonaka e Takeuchi (1997) existem duas dimensões da Criação do Conhecimento, a ontológica e a epistemológica. A primeira dimensão corresponde à premissa de que o conhecimento é criado por indivíduos e de que não existe uma criação do conhecimento na organização sem os sujeitos nela inseridos. A segunda dimensão baseia-se no conhecimento tácito e conhecimento explícito, de acordo com Michael Polanyi (1966).

Conforme Nonaka e Takeuchi:

O conhecimento tácito é pessoal, específico ao contexto e, assim, difícil de ser formulado e comunicado. Já o conhecimento explícito ou "codificado" refere-se ao conhecimento transmissível em linguagem formal e sistemática (NONAKA e TAKEUCHI, 1997, p. 65).

Em outras palavras, o conhecimento tácito é mais difícil de ser transmitido por se basear em experiências pessoais, ao contrário do conhecimento explícito, que pode ser transmitido com maior facilidade por trazer mais racionalidade, como o conteúdo de um livro, por exemplo. 


\subsubsection{Aprendizado por meio da experiência}

Kolb (1984, p. 38) tinha um posicionamento sobre aprendizagem por meio da experiência, definindo-o como "um processo pelo qual o conhecimento é criado através da transformação da experiência”.

A seguir, a Figura 1 ilustra o ciclo quadrifásico de aprendizagem de Kolb.

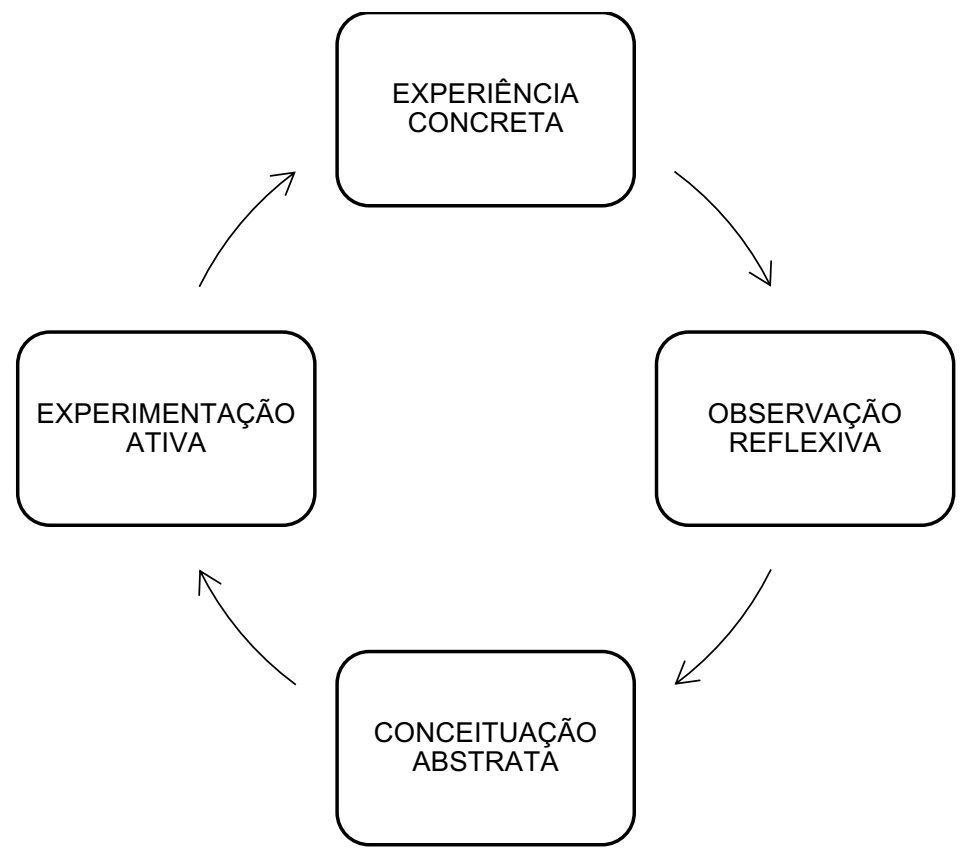

Figura 1. Ciclo Quadrifásico de Aprendizagem Baseado nos Estudos de Kolb (1984). Fonte: Kolb (1984).

A experiência concreta corresponde às novas experiências vividas pelo indivíduo; a observação reflexiva permite ao sujeito observar suas experiências, partindo de diferentes perspectivas; a conceituação abstrata indica a criação de conceitos que formam uma teoria e a experimentação ativa é a capacidade de solucionar problemas com base nas teorias.

\subsubsection{Conversão do Conhecimento}

De acordo com estudos de Nonaka e Takeuchi (1997), o processo de conversão do conhecimento tácito em explícito é explicado por meio de quatro etapas. Trata-se do Modelo SECI. A espiral do conhecimento ilustra o avanço das dimensões epistemológicas e ontológicas, à medida que o conhecimento é multiplicado.

Nonaka e Takeuchi (1997) desenvolveram o Modelo SECI para explicar a conversão do conhecimento que se dá por quatro modos: Socialização, Externalização, Combinação e Internalização. 
A Socialização é um processo de conversão do conhecimento tácito em conhecimento tácito, em que há um compartilhamento de experiências entre os indivíduos. Este modo gera o Conhecimento Compartilhado, como, por exemplo, modelos mentais ou habilidades técnicas compartilhadas (NONAKA e TAKEUCHI, 1997).

Já a Externalização consiste em um processo de conversão do conhecimento tácito em conhecimento explícito, utilizando metáforas, analogias, conceitos, hipóteses ou modelos com a combinação da dedução e indução, gerando o Conhecimento Conceitual.

A Combinação refere-se a um processo de conversão do conhecimento explícito em conhecimento explícito, no qual ocorre uma troca de conhecimentos por meio da comunicação, tanto pela fala quanto pela escrita. Este modo gera o Conhecimento Sistêmico que corresponde à geração de protótipos e de novas tecnologias.

A Internalização, por sua vez, é um processo de conversão do conhecimento explícito em conhecimento tácito, que corresponde ao aprender fazendo. Conforme Nonaka e Takeuchi (1997, p. 78), “para que o conhecimento explícito se torne tácito, é necessária a verbalização e diagramação do conhecimento sob a forma de documentos, manuais ou histórias orais". Essa documentação do conhecimento permite uma fácil transmissão de conhecimento de um indivíduo para outro. A Internalização corresponde ao Conhecimento Operacional, como, por exemplo, a implementação de novas políticas.

O Conhecimento Compartilhado, o Conhecimento Conceitual, o Conhecimento Sistêmico e o Conhecimento Operacional são denominados "conteúdos do conhecimento", de acordo com Nonaka e Takeuchi (1997), e interagem entre si na espiral de criação do conhecimento.

Segundo Nonaka e Takeuchi (1997, p. 79), “a criação do conhecimento organizacional é uma interação contínua e dinâmica entre o conhecimento tácito e o conhecimento explícito". A espiral do conhecimento (Figura 2) ilustra o aumento da escala, à medida que se elevarem os níveis ontológicos diante da interação entre conhecimento tácito e explícito.

A base do conhecimento organizacional está no conhecimento tácito dos indivíduos. A partir dos quatro modos de conversão do conhecimento, há uma ampliação do conhecimento tácito, saindo do nível individual e alcançando níveis ontológicos superiores. 


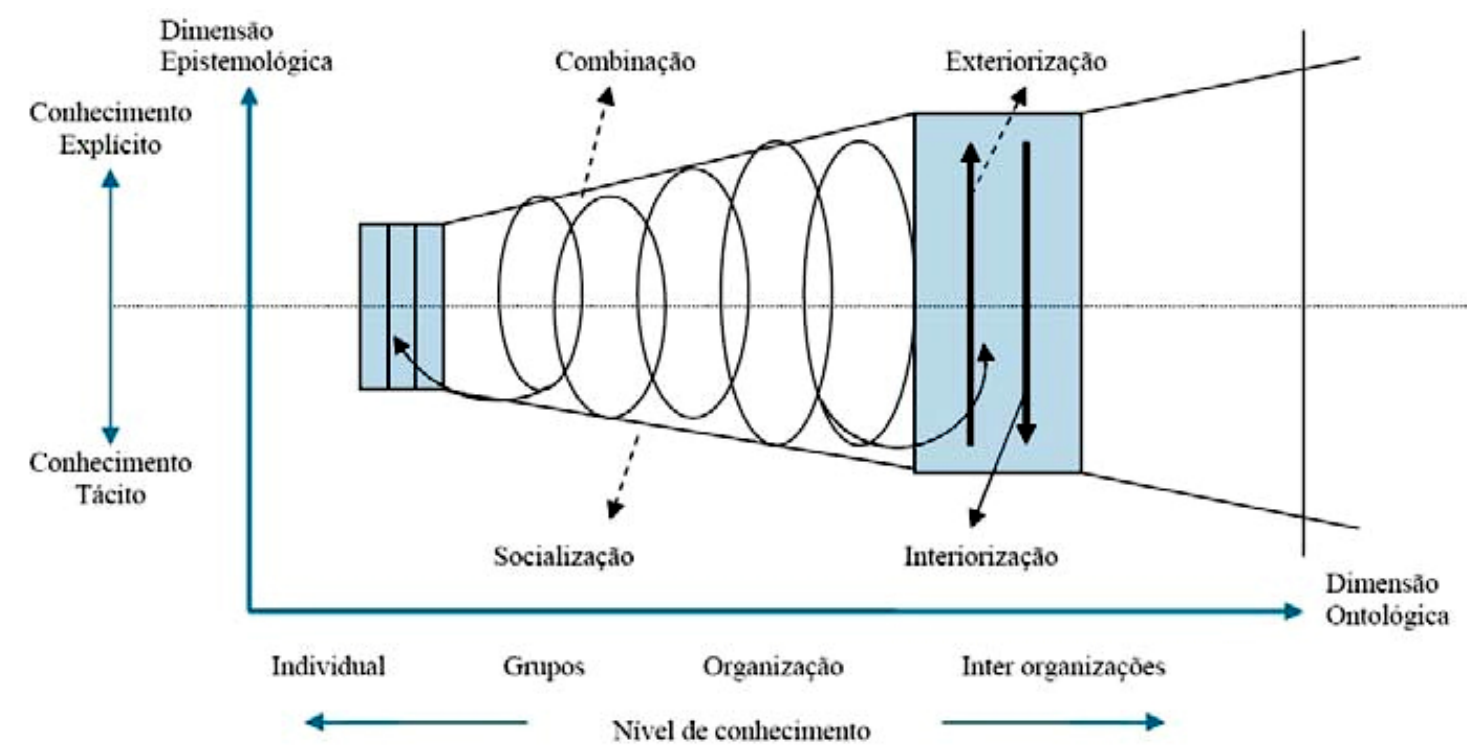

Figura 2. Espiral de Criação do Conhecimento Organizacional. Fonte: Nonaka e Takeuchi (1997).

Dentre as barreiras à Gestão do Conhecimento, Gomide e Alves (2017) destacam a dificuldade no relacionamento de forma colaborativa entre as pessoas e os grupos, diante da dinâmica do capitalismo, objetivando o lucro e o sucesso. O conhecimento tornou-se o diferencial competitivo das organizações. Esse conhecimento vem das pessoas e do relacionamento entre elas. Cabe ao líder, orientar seus liderados e "construir visões de futuro que sejam compreendidas e legitimadas pelo grupo" (ZANELLI e SILVA, 2012, p. 76), promovendo tensão criativa ${ }^{7}$.

Promover a interação entre as pessoas gera um fortalecimento nas relações interpessoais e, consequentemente, na troca de experiências e na ampliação do conhecimento, garantindo a competitividade da organização.

Diante do levantamento bibliográfico realizado, este estudo pretende apresentar características que o indivíduo pertencente à Geração Y espera de um líder e suas percepções sobre a Gestão do Conhecimento no ambiente de trabalho.

\section{MATERIAIS E MÉTODOS}

Para esta pesquisa, foi adotada uma abordagem exploratória e descritiva. Segundo Gil (2011, p. 27), as pesquisas exploratórias buscam "desenvolver, esclarecer e modificar

\footnotetext{
${ }^{7}$ Tensão criativa é a energia gerada por uma ou mais pessoas ao adquirirem consciência entre a visão e a realidade (SENGE, 2017; ZANELLI e SILVA, 2012).
} 
conceitos e ideias", enquanto as pesquisas descritivas estudam características de um determinado grupo.

A busca pela compreensão dos fenômenos que permeiam a Geração Y permitiu uma pesquisa com abordagem qualitativa, pois o foco é investigar o ponto de vista que os participantes têm em relação ao líder e à gestão do conhecimento no trabalho, cabendo ao pesquisador coletar e analisar os dados obtidos (GODOY, 1995; GODOI, BANDEIRA-DEMELLO e SILVA, 2006).

A amostragem por acessibilidade ou por conveniência foi adotada nesta pesquisa, permitindo a seleção da amostra e representando o universo sem qualquer rigor estatístico (GIL, 2011).

Após a definição da metodologia de pesquisa e do tipo de amostragem, foi desenvolvido um questionário com 44 questões, sendo 42 de múltipla escolha e 2 abertas na ferramenta Google Forms, baseando-se em elementos da Escala de Satisfação no Trabalho (EST) e da Escala de Gestão do Conhecimento (EGC), conforme estudos de Siqueira (2008) e Pais (2014). Foi aplicado um pré-teste com três pessoas escolhidas aleatoriamente, as quais não fizeram parte da amostra definitiva, visando à verificação de falhas na redação do questionário, de acordo com Gil (2011).

Após o desenvolvimento do questionário por meio da ferramenta Google Forms, houve a divulgação eletrônica do recrutamento do público-alvo - jovens entre 18 e 38 anos (Geração Y) que estejam trabalhando ou que tiveram alguma experiência profissional durante 15 dias, entre 10 de março e 24 de março de 2018. O formulário foi respondido por 35 pessoas.

Das 35 pessoas participantes da pesquisa, 66\% são do sexo feminino e $34 \%$ do sexo masculino. $46 \%$ dos participantes possuem entre 3 a 5 anos de experiência profissional. A maior parte dos respondentes possui ensino superior incompleto/cursando ou ensino superior completo, correspondendo a $46 \%$ e $37 \%$, respectivamente.

\section{ANÁLISE DOS DADOS E RESULTADOS}

Em relação à satisfação no trabalho, as questões contidas nos formulários tinham como objetivo identificar o grau de contentamento do colaborador diante de cinco dimensões: 
satisfação com os colegas, satisfação com o salário, satisfação com a chefia, satisfação com a natureza do trabalho e satisfação com as promoções.

Siqueira (2008) afirma que existem dois modelos de questionários, sendo o modelo completo e o reduzido com 25 e 15 questões, respectivamente. Para esta pesquisa, foi utilizado o modelo reduzido. As questões fechadas apresentadas no formulário tinham como respostas os seguintes níveis, com valores de 1 a 7: totalmente insatisfeito; muito insatisfeito; insatisfeito; indiferente; satisfeito; muito satisfeito e totalmente satisfeito.

Cinco escores são obtidos diante da aplicação da EST, nos quais, no modelo reduzido, três questões representavam uma dimensão. Conforme Siqueira (2008), quanto maior o escore médio obtido, maior será o grau de satisfação do trabalhador diante da dimensão estudada. Sendo assim, o escore médio com valores entre 1 e 3,9 significa um grau de insatisfação; valores entre 4 e 4,9 demonstram indiferença e valores entre 5 e 7 indicam satisfação.

O quadro 1, a seguir, apresenta os resultados obtidos diante da pesquisa.

\begin{tabular}{|l|l|l|l|}
\hline Dimensões & Média & \multicolumn{1}{|l|}{ Resultado } & \multicolumn{1}{l|}{ Itens } \\
\hline Satisfação com os colegas & 4,62 & Indiferença & 1,4 e 14 \\
\hline Satisfação com o salário & 3,20 & Insatisfação & 3,6 e 11 \\
\hline Satisfação com a chefia & 4,62 & Indiferença & 10,12 e 15 \\
\hline Satisfação com a natureza do trabalho & 4,24 & Indiferença & 5,8 e 13 \\
\hline Satisfação com as promoções & 2,98 & Insatisfação & 2,7 e 9 \\
\hline
\end{tabular}

Quadro 1 - Resultado da Escala de Satisfação no Trabalho. Fonte: Elaborado pela autora.

Para obter a média de cada dimensão, foi calculada a soma das médias de cada item correspondente, seguida da divisão da quantidade de itens - para a versão reduzida, são 3 itens.

Observou-se que as médias da satisfação com os colegas, com a chefia e com a natureza do trabalho indicaram indiferença, e as médias de satisfação com o salário e com as promoções apresentaram insatisfação por parte dos respondentes.

Em relação à $\mathrm{GC}$, as questões apresentadas tinham como objetivo analisar quatro fatores, conforme Pais (2014): orientação cultural para o conhecimento; orientação competitiva; práticas formais de gestão do conhecimento e práticas informais de gestão do conhecimento. 
Foi considerada a versão reduzida da EGC para aplicação do questionário, com 22 itens. As respostas variavam entre 1 e 5, em uma escala crescente de aplicação da GC, de acordo com a percepção do respondente. A média de cada fator é obtida conforme o raciocínio de Pais (2014), com a adição das respostas dadas por todos os respondentes dos itens seguida pela divisão do valor total pela quantidade de itens do fator.

\section{Fatores}

\section{Média Itens}

\begin{tabular}{|l|l|l|}
\hline 1 - Orientação cultural para o conhecimento & 3,53 & $2,6,10,13,14,18$ e 19 \\
\hline 2 - Orientação competitiva & 3,19 & $5,8,9$ e 22 \\
\hline 3 - Práticas formais de GC & 3,08 & $3,7,11,16,17$ e 21 \\
\hline 4 - Práticas informais de GC & 3,43 & $1,4,12,15$ e 20 \\
\hline
\end{tabular}

Quadro 2 - Resultado da Escala de Gestão do Conhecimento. Fonte: Elaborado pela autora.

Analisando as médias obtidas no quadro 2, destaca-se que a média 3,53, que corresponde ao fator 1 (Orientação cultural para o conhecimento), indica que é um fator que se aplica muito à organização cujos respondentes trabalham. Ou seja, trata-se de um fator que dá importância aos valores, com processos definidos e que devem ser seguidos, criando uma cultura voltada ao conhecimento e visando a uma melhoria do desempenho da organização (PAIS, 2014).

A média de 3,19, correspondente ao fator 2 (Orientação competitiva), indica que é um fator que se aplica moderadamente à organização dos respondentes. Isso significa que a GC não está sendo adotada como um diferencial competitivo pela organização, sem se orientar para o ambiente externo (clientes e concorrência).

O fator 3 (Práticas formais de GC) apresentou uma média de 3,08, indicando que ser um fator que se aplica moderadamente à organização em questão. Esse fator apresenta o quanto os processos estão formalizados e o conhecimento é compartilhado de forma explícita, na maior parte.

A média de 3,43, no fator 4 (práticas informais de GC), corresponde ao fator que se aplica moderadamente à organização em questão, o que significa que o conhecimento tácito é transmitido, na maior parte, por meio das interações.

Por meio de uma questão aberta, os respondentes puderam descrever quais características são esperadas em um líder. Os resultados são apresentados no gráfico abaixo. 


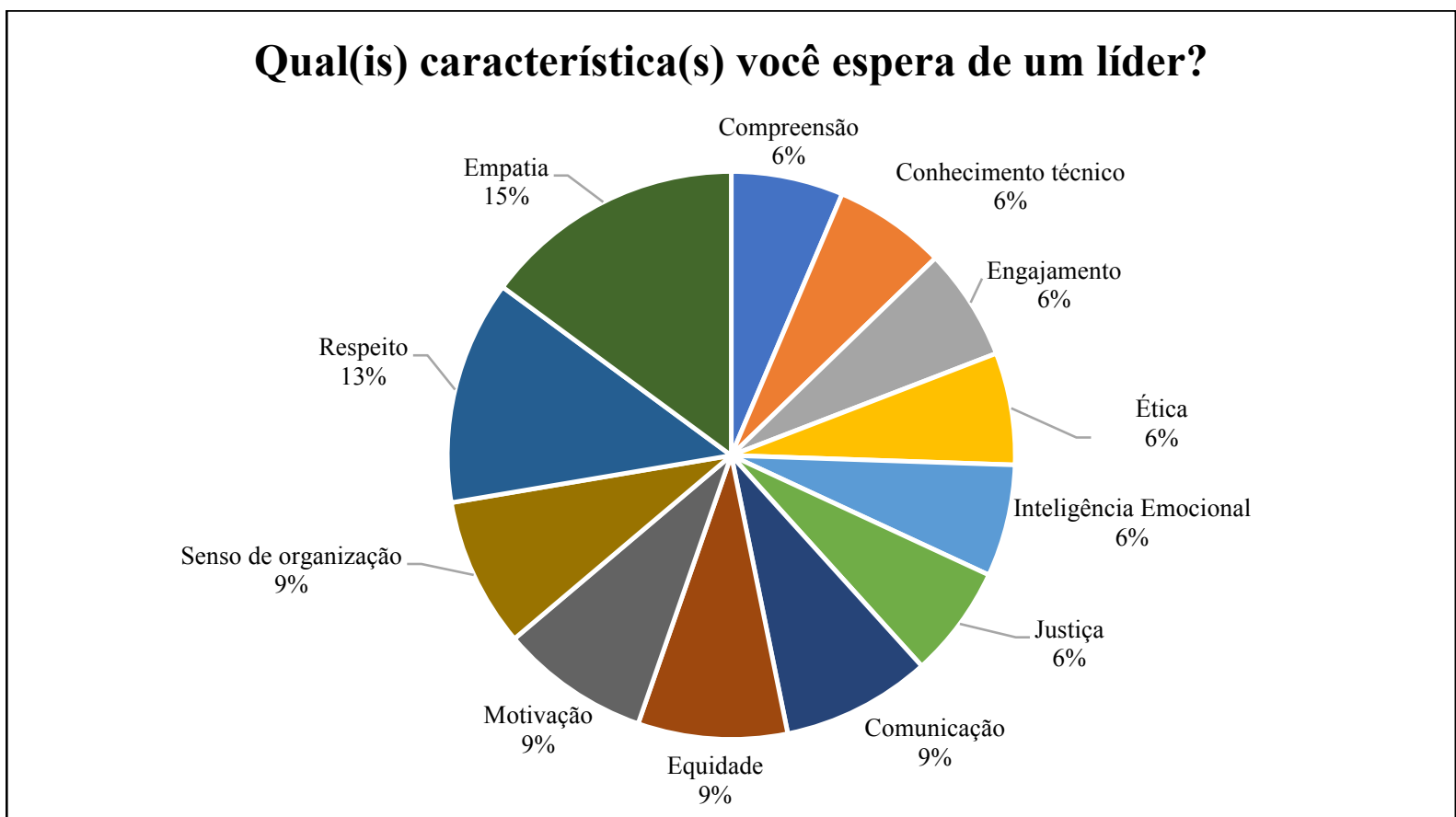

Gráfico 1 - Distribuição dos respondentes quanto às características esperadas de um líder. Fonte: Elaborado pela autora.

Dentre as características apresentadas pelos respondentes, foram apontadas no gráfico as 12 que mais foram mencionadas por mais de um entrevistado, tendo como destaque a empatia $^{8}$, com aproximadamente $15 \%$, correspondendo a 7 pessoas, seguido pelo respeito, com aproximadamente 13\%. Aspectos como organização, democracia, lealdade, responsabilidade, paciência, resiliência, pontualidade e integridade também foram mencionados por pelo menos um respondente.

Foi questionado aos respondentes se a organização em que trabalham adota práticas de GC. Dos 35 participantes, aproximadamente 51\% afirmaram que a organização em que trabalham adota práticas de GC, correspondendo a 18 pessoas, contra aproximadamente $49 \%$, isto é, 17 pessoas que afirmaram que a organização em que estão não adota práticas de GC.

Para os 18 respondentes que afirmaram que a empresa em que trabalham adota práticas de GC, foi solicitada, em forma de questão aberta, as práticas adotadas pelas empresas, permitindo mencionar mais de uma, apresentando os resultados a seguir: em primeiro lugar, aproximadamente $89 \%$ mencionaram os treinamentos (presenciais e/ou à distância); os layouts com espaços abertos e compartilhados com aproximadamente 50\%; a

\footnotetext{
${ }^{8}$ Empatia é a capacidade de perceber o que as outras pessoas sentem (ROBBINS, 2005, p. 94).
} 
universidade corporativa com aproximadamente $22 \%$ e o programa de coaching com aproximadamente $17 \%$.

\section{CONSIDERAÇÕES FINAIS}

O período Pós-Moderno é marcado por mudanças sociais cujos indivíduos estão conectados às novas tecnologias, reduzindo a relação espaço-tempo e aumentando, cada vez mais, o consumo por meio das ferramentas midiáticas. Consequentemente, torna-se necessário multiplicar polos produtivos para atender as demandas.

Ao mesmo tempo, temos a inserção da Geração Y no mercado de trabalho. Ao contrário das gerações anteriores, esses jovens buscam um significado no trabalho e acreditam que as organizações devem se adaptar a eles e não o contrário. Embora tenham maior facilidade ao uso das tecnologias e ao acesso à informação, é uma geração que tem medo de errar, necessitando feedbacks constantes.

Cada indivíduo é detentor de um conhecimento que é ampliado à medida que passa por interações, conforme a espiral de criação do conhecimento, de Nonaka e Takeuchi (1997). A organização vista isoladamente não é capaz de criar conhecimento, dependendo das pessoas que a compõe. Para que esse conhecimento seja disseminado de maneira eficaz, cabe ao líder guiar sua equipe e engajá-la de forma a contribuir para o desenvolvimento da organização. A mudança não começa apenas no topo da hierarquia: depende, também, de quem está na base da organização (SENGE, 2017; ZANELLI e SILVA, 2012).

Ao contrário da administração clássica, na qual o trabalhador era visto como uma máquina, atualmente, este é considerado peça fundamental para o desenvolvimento da organização. Novas equipes autônomas de trabalho, hierarquia horizontalizada, desenvolvimento de gestores e diálogos entre os colaboradores das mais diversas áreas organizacionais são exemplos de tendências que permitem uma evolução nas práticas de Gestão do Conhecimento (ZANELLI e SILVA, 2012).

O líder não nasce pronto; ele é capaz de se desenvolver com o tempo (CORTELLA e MUSSAK, 2012). Este estudo permitiu que os líderes que conduzem a Geração Y conheçam os jovens que estão no ambiente organizacional e aproveitem, da melhor forma possível, o 
potencial de cada um, e façam com que eles se sintam inseridos na equipe, oferecendo maior liberdade de interação.

Com base nos resultados da pesquisa, também é preciso refletir sobre os mecanismos que possam engajar os jovens da Geração Y que demonstram insatisfação ou indiferença nas cinco dimensões estudadas. Esses indivíduos possuem muitas expectativas ao iniciarem um trabalho e quando não são correspondidas rompem o contrato psicológico (ZANELLI e SILVA, 2012).

É importante ressaltar que esta pesquisa não esgota o tema proposto, devido ao fato de que a amostra apresentada com 35 sujeitos não justifica uma generalização dos fatos, exigindo uma análise mais profunda do tema, trazendo luz a novos estudos correlatos. Alguns jovens da Geração Y estão ocupando posições de liderança e, como desafio, terão de compreender a Geração $Z^{9}$, que está entrando no mercado de trabalho.

\section{REFERÊNCIAS}

ANDERSON, Perry. As origens da pós-modernidade. Rio de Janeiro: Jorge Zahar, 1999.

BAUMAN, Zygmunt. O mal-estar da pós-modernidade. Rio de Janeiro: Jorge Zahar, 1998.

. Globalização: as consequências humanas. Rio de Janeiro: Jorge Zahar, 1999.

. Modernidade líquida. Rio de Janeiro: Jorge Zahar, 2001.

. Tempos líquidos. Rio de Janeiro: Jorge Zahar, $2007 \mathrm{a}$.

. Vida líquida. Rio de Janeiro: Jorge Zahar, 2007b.

. Medo líquido. Rio de Janeiro: Jorge Zahar, 2008a.

. Vida para consumo: a transformação das pessoas em mercadoria. Rio de Janeiro: Jorge Zahar, 2008b.

BENDASSOLI, Pedro F.; SERAFIM, Mauricio C. Bebezões a bordo. GV Executivo, vol. 6, n. 1, p. 49-53, jan-fev 2007.

\footnotetext{
${ }^{9}$ Geração Z: Corresponde aos indivíduos nascidos entre os anos 2000 a 2010. É uma geração mais conectada às tecnologias em relação à Geração Y (OLIVEIRA, 2016).
} 
BONIFÁCIO, Taynã Malaspina de Freitas. Geração Y e a busca de sentido na modernidade líquida: eles não são todos iguais e estão mudando as relações de trabalho. Curitiba: Juruá, 2014.

CAVALCANTI, Vera Lucia et al. Liderança e motivação. 3. ed. Rio de Janeiro: Editora FGV, 2009.

CIA DE TALENTOS. Carreira dos sonhos 2017. Disponível em: < http://www.carreiradossonhos.com.br/pdf/CS2017_Hotsite_final.pdf $>$. Acesso em: 18 jan. 2018.

CORTELLA, Mario Sergio; MUSSAK, Eugenio. Liderança em foco. 7. ed. Campinas: Papirus, 2012.

DICIONÁRIO MICHAELIS. Significado de status quo. Disponível em: $<$ https://michaelis.uol.com.br/moderno-portugues/busca/portugues-brasileiro/statu/>. Acesso em: 11 ago. 2018.

EAGLETON, Terry. As ilusões do pós-modernismo. Rio de Janeiro: Jorge Zahar, 1996.

GIL, Antonio Carlos. Métodos e técnicas de pesquisa social. 6. ed. São Paulo: Atlas, 2011.

GODOI, Christiane Kleinübing, BANDEIRA-DE-MELLO, Rodrigo, SILVA, Anielson Barbosa. Pesquisa qualitativa em estudos organizacionais: paradigmas, estratégias e métodos. São Paulo: Saraiva, 2006.

GODOY, Arilda Schmidt. Introdução à pesquisa qualitativa e suas possibilidades. Revista de Administração de Empresas, São Paulo, v. 35, n. 2, p. 57-63, mar-abr. 1995.

GOMIDE, Cibele Pacheco; ALVES, Antônio Fernando Gomes. A importância do desenvolvimento de aspectos socioemocionais para a gestão do conhecimento nas organizações. Revista Triângulo, v. 10, n. 2, p. 122-141, jul-dez. 2017.

HARVEY, David. Condição pós-moderna: uma pesquisa sobre as origens da mudança cultural. 17. ed. São Paulo: Edições Loyola, 2008.

KOLB, D. A. Experimental learning: experience as the source of learning and development. New Jersey: Prentice Hall, 1984.

LANCASTER, Lynne; STILLMAN, David. O Y da questão: como a geração Y está transformando o mercado de trabalho. São Paulo: Saraiva, 2011.

LIPKIN, Nicole A.; PERRYMORE, April J. A geração Y no trabalho: como lidar com a força de trabalho que influenciará definitivamente a cultura da sua empresa. Rio de Janeiro: Elsevier, 2010.

LIPOVETSKY, Gilles. Os tempos hipermodernos. São Paulo: Bararolla, 2004. 
LOMBARDÍA, Pilar García; STEIN, Guido e PIN, José Ramón. Politicas para dirigir a los nuevos profesionales: motivaciones $y$ valores de la generacion $Y$. Documento de investigación. Mayo, 2008. Disponível em: <https://core.ac.uk/download/pdf/6536374.pdf>. Acesso em: 23 set. 2017.

LONGO, Rose Mary Juliano et al. Gestão do conhecimento: a mudança de paradigmas empresariais no século XXI. São Paulo: Editora Senac, 2014.

LYOTARD, Jean-François. O pós-moderno. 3. ed. Rio de Janeiro: José Olympio, 1988.

NONAKA, Ikujiro; TAKEUCHI, Hirotaka. Criação de conhecimento na empresa: como as empresas japonesas geram a dinâmica da inovação .18. ed. -. Rio de Janeiro: Elsevier, 1997.

MORENO, B. S. Gestão de pessoas: tendências e desafios na nova missão do RH de hoje. UNOPAR Cient., Coênc. Jurid. Empres., Londrina, v. 3., n. 2, p. 33-38, set. 2002.

OLIVEIRA, Sidney. Geração Y: o nascimento de uma nova versão de líderes. São Paulo: Integrare Editora, 2010.

$\overline{\text { Editora, }} 2016$.

Gerações: encontros, desencontros e novas perspectivas. São Paulo: Integrare

PAIS, Leonor. Gestão do conhecimento. In: SIQUEIRA, Mirlene Maria Matias (Org.) Novas medidas do comportamento organizacional: ferramentas de diagnóstico e de gestão. Porto Alegre: Artmed, 2014. p. 193-208.

POLANYI, M. The tacit dimension. London: Routledge \& Kegan Paul, 1966.

ROBBINS, Stephen P. Comportamento organizacional. São Paulo: Pearson Prentice Hall, 2005.

SANTOS, Boaventura de Sousa. Pela mão de Alice: o social e o político na pósmodernidade. 11. ed. São Paulo: Cortez, 2006.

SENGE, P. M. A quinta disciplina: arte e a prática da organização que aprende. 33 ed. -. Rio de Janeiro: BestSeller, 2017.

SIGNIFICADOS. Significado de geração. Disponível em: $<$ http://www.significados.com.br/?s=geração>. Acesso em: 01 fev. 2018.

SIQUEIRA, M. M. M. Medidas do comportamento organizacional: ferramentas de diagnóstico e de gestão. Porto Alegre: Artmed, 2008.

SVEIBY, Karl Erik. A Nova Riqueza das Organizações. Rio de Janeiro: Campus, 1998.

ZANELLI, José Carlos; SILVA, Narbal. Interação humana e gestão: a construção psicossocial das organizações de trabalho. 3. ed. São Paulo: Casa do Psicólogo, 2012.

\begin{tabular}{|l|l|l|l}
$\mathrm{v} .11$ & $\mathrm{n} .2$
\end{tabular}


ZIMMER, Marco Vinicius; LEIS, Rodrigo Pinto. Gestão do conhecimento no Brasil: o que está sendo produzido e para onde caminha a área. In: ANTONELLO, Claudia Simone; GODOY, Arilda Schmidt. Aprendizagem Organizacional no Brasil. Porto Alegre: Bookman, 2011, cap. 7, p. 160-182. 